\title{
Cutting Edge Therapeutic Insights Derived from Molecular Biology of Pediatric High-Grade Glioma and Diffuse Intrinsic Pontine Glioma (DIPG)
}

\author{
Cavan P. Bailey ${ }^{1,2,3} \mathbb{C}^{\text {, }}$, Mary Figueroa ${ }^{1,2,3}$, Sana Mohiuddin ${ }^{4}$, Wafik Zaky ${ }^{4}$ and \\ Joya Chandra 1,2,3,* \\ 1 Department of Pediatrics—Research, University of Texas MD Anderson Cancer Center, Houston, TX 77030, \\ USA; cpbailey@mdanderson.org (C.P.B.); mfigueroa1@mdanderson.org (M.F.) \\ 2 The University of Texas MD Anderson Cancer Center, UTHealth Graduate School of Biomedical Sciences, \\ Houston, TX 77030, USA \\ 3 Center for Cancer Epigenetics, University of Texas MD Anderson Cancer Center, Houston, TX 77030, USA \\ 4 Department of Pediatrics-Patient Care, University of Texas MD Anderson Cancer Center, Houston, \\ TX 77030, USA; smohiuddin@mdanderson.org (S.M.); wzaky@mdanderson.org (W.Z.) \\ * Correspondence: jchandra@mdanderson.org; Tel.: +1-713-563-5405
}

Received: 8 August 2018; Accepted: 15 October 2018; Published: 18 October 2018

\begin{abstract}
Pediatric high-grade glioma (pHGG) and brainstem gliomas are some of the most challenging cancers to treat in children, with no effective therapies and 5-year survival at $\sim 2 \%$ for diffuse intrinsic pontine glioma (DIPG) patients. The standard of care for pHGG as a whole remains surgery and radiation combined with chemotherapy, while radiation alone is standard treatment for DIPG. Unfortunately, these therapies lack specificity for malignant glioma cells and have few to no reliable biomarkers of efficacy. Recent discoveries have revealed that epigenetic disruption by highly conserved mutations in DNA-packaging histone proteins in pHGG, especially DIPG, contribute to the aggressive nature of these cancers. In this review we pose unanswered questions and address unexplored mechanisms in pre-clinical models and clinical trial data from pHGG patients. Particular focus will be paid towards therapeutics targeting chromatin modifiers and other epigenetic vulnerabilities that can be exploited for pHGG therapy. Further delineation of rational therapeutic combinations has strong potential to drive development of safe and efficacious treatments for $\mathrm{pHGG}$ patients.
\end{abstract}

Keywords: pediatric; high-grade glioma; DIPG; therapeutics; epigenetics; clinical trial

\section{Pathology of Pediatric High-Grade Gliomas and Diffuse Intrinsic Pontine Gliomas (DIPG)}

Malignancies of the central nervous system (CNS) have been a constant challenge for clinicians and researchers alike. Due to their complex morphology and relative resistance to therapies, patient mortality is among the highest of all cancers. Pediatric high-grade gliomas (pHGG) constitute about $11 \%$ of all pediatric CNS tumors, with an incidence rate of 0.59 per 100,000 [1]. A subset of pHGG are brainstem gliomas, of which the majority are categorized historically as diffuse intrinsic pontine glioma (DIPG) or diffuse midline glioma (DMG), per the new nomenclature. Five-year survival rates for pHGG as a whole are 28\% [1], but are much more dismal for DIPG at 2\% [2]. HGG typically arise from astrocytic origins, including glial, oligodendrocytes, and ependymal cells. These tumors are classified by the World Health Organization (WHO) as either grade III or IV meaning that they are highly malignant tumors with characteristic findings such as hypercellularity, nuclear atypia, and high mitotic activity with or without microvascular proliferation and pseudopalisading necrosis [3]. HGG include a variety of heterogeneous lesions with differing histology, including anaplastic astrocytoma 
(WHO Grade III), glioblastoma (WHO grade IV) and diffuse midline glioma, H3-K27M mutant (grade IV) as the most common types. Other less common types include anaplastic oligodendroglioma (grade III), anaplastic ganglioglioma (grade III), anaplastic pleomorphic xanthoastrocytoma (grade III), giant cell glioblastoma (grade IV), and gliosarcoma (grade IV) [3-5].

\section{Molecular Alterations of pHGG and DIPG}

Efforts to amass tissue specimens from pHGG patients and apply DNA and RNA sequencing technology have reclassified pHGG pathology. Previously, molecular data was not used to classify brain tumors [3], and for pHGG the only parameters known to correlate with patient outcome are extent of surgical resection and histological grade [6,7]. While useful, these measurements cannot inform pre-clinical molecular research or influence targeted therapeutic decisions. The 2016 WHO reclassification of brain tumors [3] incorporates sequencing data for a more complete picture of pHGG pathology. Broadly, pHGG possess mutations in key epigenetic pathways and signaling kinases, and this new understanding of molecular mechanisms has led to clinical trials designed to target these specific vulnerabilities (Table 1).

Early attempts at large-scale profiling of pediatric gliomas utilized comparative genomic hybridization (CGH) techniques that enable detection of deletions and amplifications in a sample with a resolution of approximately 50 kilobases [8]. This study helped confirm that pediatric high-grade gliomas rely less on EGFR amplification, which adult grade IV gliomas often possess, and instead rely more on platelet-derived growth factor receptor (PDGFR) amplifications. Another new observation was pediatric high-grade gliomas featuring fewer aberrations in the RTK/PI3K/p53/RB "core signaling pathways" seen in adult glioma. A compelling finding was that a distinct phenotypic category $(\sim 20 \%$ of their cohort) was found to have a "stable genome" with no detectable copy number alterations. This group not only was in stark contrast to the consistently highly-reconfigured genomes of adult gliomas, but featured improved survival over the "amplified" subtypes in the pediatric range [8]. Presence of disease without extensive genomic rearrangement put forth the idea that perhaps very specific and very powerful mutations could potentially be drivers of gliomagenesis and glioma progression.

Two landmark studies were concurrently published in early 2012 that revealed unique features of pediatric gliomas: they possess mutations in the histone H3 alleles H3.1 (HIST1H3B) and H3.3 (H3F3A), occurring either at (lysine 27; $\mathrm{K}$ to M; H3.1 and H3.3) or near (glycine 34; G to R/V; H3.3 only), a post-translational histone modification point. The K27M variant was found in younger patients (median age, 9 years), midline location including thalamus and brainstem while the G34R/V was more indicative of an adolescent population (median age, 20 years) and hemispheric in location. Due to the co-occurrence of the H3.3 mutation with TP53 mutations (100\% of G34R/V, $82 \%$ of K27M) and its conserved nature across patients, this led the authors to believe this is a driver mutation in pHGG $[9,10]$. These mutations were further found at an even higher prevalence in DIPG, with two independent studies reporting 71\% [10] and 78\% [11] occurrence of the K27M mutation in a histone H3 variant. Notably, the G34R/V mutation was not found in DIPG, confirming results that it is only seen in supratentorial pHGG. Later findings in 2014 by four separate groups revealed mutations in the activin receptor-like kinase-2 (ACVR1) to co-segregate with younger H3.1-K27M, TP53 wild-type patients whom had slightly improved survival versus other DIPG genotypes [12-15]. All seven studies mentioned the need for further functional validations of these mutations, and encouraged extensive experimental investigation of their mechanistic impact and role in glioma development. 
Table 1. Subtypes of pediatric high-grade gliomas, relevant mutations and features, and pediatric clinical trials designed to target these mutations. Diffuse intrinsic pontine glioma (DIPG), histone H3 K27M variant (H3-K27M), TP53, ACVR1, activin receptor-like kinase-2 (ALK2), ATRX-DAXX, platelet-derived growth factor receptor A (PDGFRA), pan-histone deacetylase (HDAC), FGFR1, MAPK, BRAF, MEK, NTRK, TRK, mTOR, IDH1, MYCN, TERT, SETD2, WEE1, NCT.

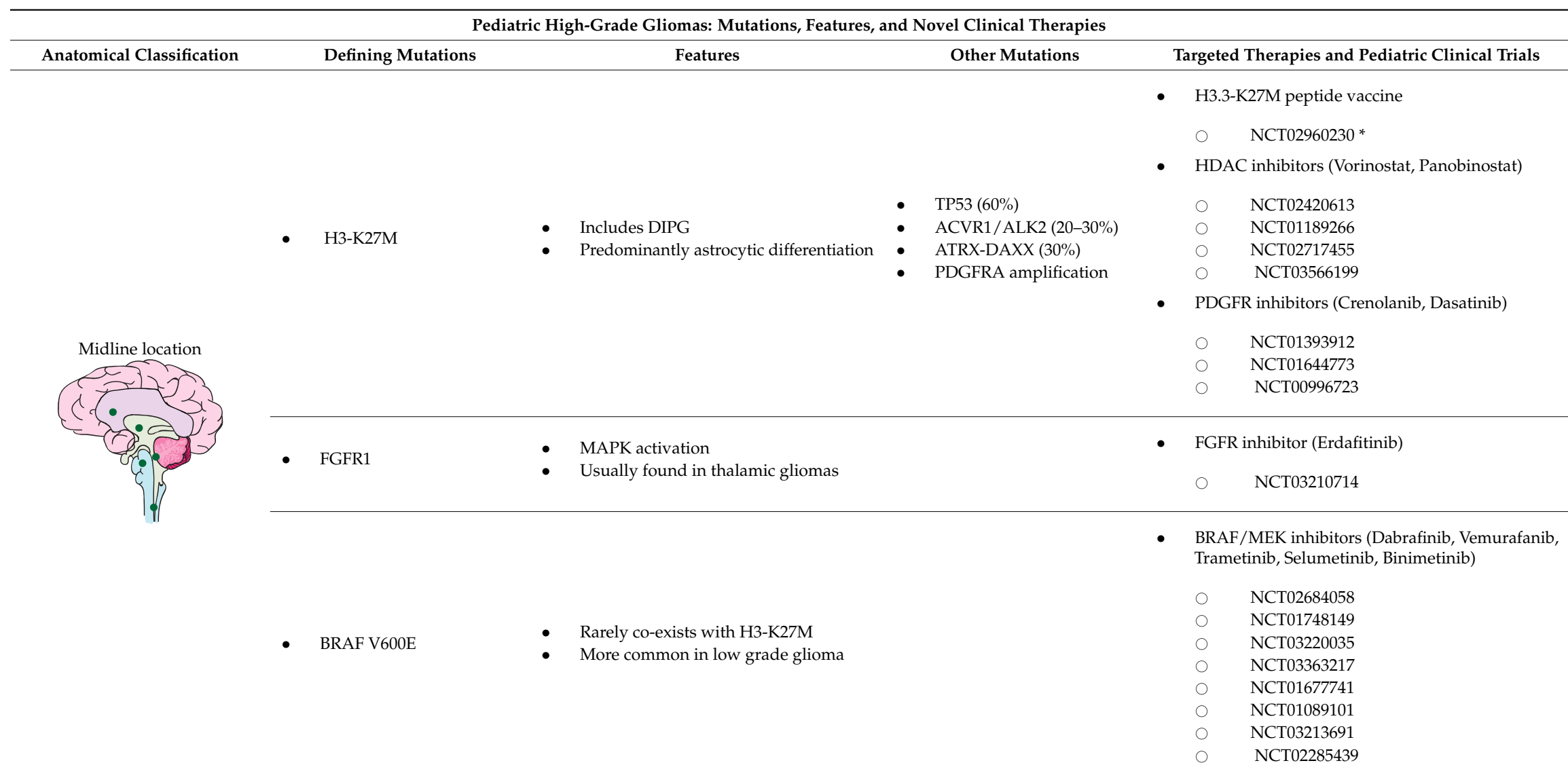


Table 1. Cont

\begin{tabular}{|c|c|c|c|c|}
\hline \multicolumn{5}{|c|}{ Pediatric High-Grade Gliomas: Mutations, Features, and Novel Clinical Therapies } \\
\hline Anatomical Classification & Defining Mutations & Features & Other Mutations & Targeted Therapies and Pediatric Clinical Trials \\
\hline \multirow{4}{*}{ Hemispheric location } & - $\mathrm{H} 3-\mathrm{G} 34 \mathrm{R} / \mathrm{V}$ & $\begin{array}{ll}\text { - } & 15 \% \\
& \text { Histologically homogenous appearance }\end{array}$ & $\begin{array}{ll}- & \text { ATRX/DAXX }(100 \%) \\
\text { - } & \text { TP53 }(90 \%) \\
& \text { NTRK fusion }\end{array}$ & $\begin{array}{ll}\text { - } & \text { TRK inhibitors (Larotectinib, Entrectinib) } \\
& \text { N } \\
\circ & \text { NCT03213704 } \\
\circ & \text { NCT02637687 } \\
\circ & \text { NCT03215511 } \\
\circ & \text { NCT02650401 }\end{array}$ \\
\hline & - IDH1 mutant & $\begin{array}{ll}\text { - } & \text { Small population } \\
\text { Better survival than wild type }\end{array}$ & & $\begin{array}{l}\text { - } \text { mTOR inhibitor (Everolimus) } \\
\quad \quad \text { NCT01734512 }\end{array}$ \\
\hline & - H3/IDH wild type & & $\begin{array}{ll}\text { - } & \text { MYCN amplification } \\
\text { - } & \text { TP53 } \\
\text { - } & \text { PDGFRA } \\
& \text { TERT }\end{array}$ & \\
\hline & - $\quad \operatorname{SETD} 2(15 \%)$ & - Mutually exclusive with $\mathrm{H} 3-\mathrm{G} 34 \mathrm{R} / \mathrm{V}$ & & - WEE1 inhibitor (Adavosertib) \\
\hline
\end{tabular}

* All NCT entries indicate trial number listed in clinicaltrials.gov. 
Other mutations co-occur with the histone mutations in pHGG, including ATRX, SETD2, and TP53 mutations (Table 1). Adult HGG, which do not possess histone mutations, are more likely to have CDKN2A/B deletions, IDH1/2 mutations, EGFR amplification and PTEN loss. DIPGs follow the pHGG molecular pattern but are further enriched for TP53 mutation and PTEN loss, lack SETD2 mutations, and possess PDGFRA amplification (Table 1) [16,17]. Alterations in cell growth pathways are seen in some pHGGs, including $B R A F$ and FGFR1 mutations and gene fusions among the TRK family (NTRK1/2/3) (Table 1) [18]; however, BRAF/FGFR1 perturbations are far more prominent in pediatric low-grade gliomas (pLGGs) [19].

\section{Histone H3-K27M and G34R/V-Specific Mechanisms in pHGG}

A rigorous examination of histone $\mathrm{H} 3$ amino acid substitutions using in vitro biochemical assays, HEK-293 cell culture, and murine brain stem glioma models found that the K27M mutation can inactivate the polycomb repressive complex 2 (PRC2) via methionine/isoleucine-specific hydrophobic interactions with the active site of enhancer of zeste homolog 2 (EZH2) [20]. As such, the positive feedback loop regulating PRC2 activity is disrupted and global hypomethylation at H3K27 is observed, along with increased H3K27 acetylation. It was later found that H3.1/3.3-K27M inactivation of PRC2 can also enrich H3K27me3 at specific loci, causing either gene activation (hypo-H3K27me3) or gene suppression (enriched-H3K27me3) in unique pathways [21]. These findings were recapitulated with additional insight into the role of DNA methylation as a consequence of H3.3-K27M, as well as observance of increased H3K27me3 in intergenic regions of the genome, suggesting a possible link with miRNA or lncRNA dysregulation in H3-mutated pHGG [22].

While the K27M mutations possess a potent inhibitory effect on SET-domain containing methyltransferases, the G34R/V mutation did not recapitulate the same effect in vivo at H3K36. However, immunoprecipitated nucleosomes from the same cells showed lowered H3K36me2/3 on the G34R/V-H3.2/3 histone, but not the wild-type H3.2/3 histone in the same oligonucleosome chain [20]. SETD2 is the methyltransferase responsible for generating the H3K36me3 mark, and its interaction with G34R/V mutations has not been extensively studied (Figure 1). The H3.3K36me3 reader protein ZMYND11 cannot bind under G34R/V conditions [23]; however, further investigations of protein complex, reader, and SETD2 binding with G34R/V nucleosomes are needed to provide insight into why the G34R/V mutation does not create a hypomethylated phenotype at the H3K36 residue. 


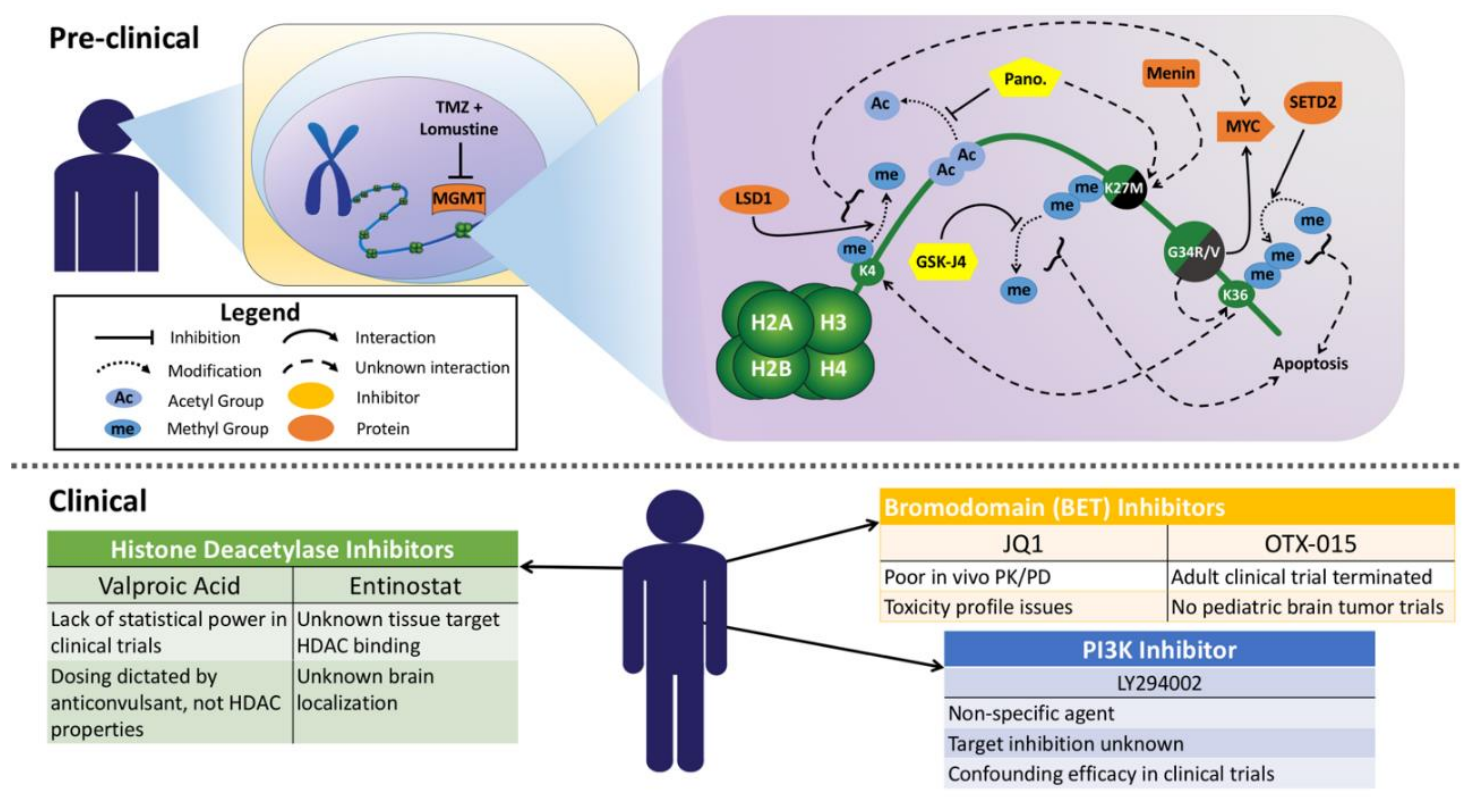

Figure 1. Unexplored pre-clinical molecular interactions and inconclusive clinical data in pediatric high-grade glioma research and trials. Temozolomide (TMZ), O-6-methylguanine-DNA methyltransferase (MGMT), lysine-specific demethylase 1 (LSD1), Pano, MYC, GSK-J4, JQ1, PK/PD, OTX-015, PI3K.

\section{Standard of Care Therapies in pHGG including DIPG}

The outcome for children with HGG remains dismal despite the use of multi-modal therapy including surgery, radiation therapy (RT) and chemotherapy. In a phase II trial that used temozolomide (TMZ) in combination with lomustine following RT, the authors observed an increase in the overall survival (OS) and event-free survival (EFS) when compared to TMZ + RT alone, but this came with higher toxicities [24]. They hypothesize treatment with multiple alkylating agents can degrade expression of de-alkylating enzymes and increase sensitivity when a second agent is used, but this has not been verified experimentally (Figure 1). Anti-angiogenic therapy with bevacizumab has shown efficacy in recurrent adult glioma [25], but not in newly diagnosed adult glioma patients [26,27] or in combination with lomustine [28]. In pHGG patients, bevacizumab was evaluated in addition to $\mathrm{TMZ}+\mathrm{RT}$ in patients with newly diagnosed non-brainstem high-grade glioma in a phase II open-label, randomized, multicenter trial (HERBY) [29]. A follow-up molecular analysis of the HERBY trial found addition of bevacizumab to TMZ + RT conferred a survival benefit only in hypermutated and $B R A F$-driven tumors that display an increase in CD8+ T-cell infiltration after therapy [30]. Notably, K27M and G34R/V tumors were "immunologically cold" in their analysis, highlighting how checkpoint blockade and other T-cell-stimulating therapies may not be a viable option for these patients.

DIPG presents a special challenge as their diffuse nature in the brainstem makes surgery not feasible [31,32]. Recent studies have shown MRI-guided stereotactic biopsy to be a safe and reliable method of molecularly characterizing a DIPG patient [33,34], and others were able to detect mutational status using cerebrospinal fluid-sourced tumor DNA [35]. Radiotherapy for DIPG can prolong survival by a few months, but ultimately RT is palliative and patients succumb to progressive disease within a year. Multiple lines of treatment have been tested in clinical trials including chemotherapy and targeted therapy without improving outcome to standard radiation alone [36]. From a clinical therapeutic perspective, it is difficult to discriminate whether the resistance of DIPG to chemotherapy is due to inherent cellular mechanisms or poor delivery of the drug to the tumor site (Table 1). This issue will be addressed later in the review by exploring cutting-edge modalities to improve drug delivery to the brain. 
Studies initially focused on TMZ resistance in pHGG led researchers to the homeobox genes HOXA9 and HOXA10, which were found to be upregulated in pediatric cell lines and correlated to TMZ resistance independent of the demethylating gene; O-6-methylguanine-DNA methyltransferase (MGMT) [37]. The pediatric TMZ-resistant cells were also found to be high in progenitor cell markers such as Nestin and CD133, possibly endowing these cells with enhancements in self-renewal and other stem-like properties. Further investigation of the HOX signature in adult glioma found that DNA methylation combined with chromosome 7 copy gains endow the adult glioma cells with aberrant HOX expression which is normally never seen past the hindbrain [38].

Similar dysregulation of HOX expression was also found in adult high-grade astrocytoma and here HOXA9/10 could be regulated in a PI3K-dependent manner that relied on epigenetic modifications. In their analysis, usage of a PI3K inhibitor decreased HOX expression while also increasing trimethylation of lysine 27 on histone $\mathrm{H} 3$ (H3K27me3) and decreasing trimethylation of lysine 4 on histone $\mathrm{H} 3$ (H3K4me3) [39]. It should be noted the authors used LY294002 to inhibit PI3K, a well-documented non-specific agent [40] that also inhibits CK2, mTOR, and GSK3 $\beta$ [41] along with bromodomains [42] (Figure 1). More recently, targeting of the PI3K pathway in DIPG either with direct chemical agents [43, 44] or by modulating the tumor microenvironment [45], has demonstrated efficacy in pre-clinical studies that have not been replicated in a small clinical trial [46]. However, there exists a wide range of drugs designed to target this pathway, and the authors note they did not measure target inhibition in their patient cohort [46].

\section{Histone H3-K27M and G34R/V-Specific Therapies}

With the recent mechanistic insights into how mutant histones poise the epigenome for later tumor development [47], thoughts turned to how to therapeutically target these phenomena and potentially bring new hope to patients with untreatable disease. The well-known oncogene MYC was one of the first targets, identified because the G34R/V mutation in H3.3 leads to enrichment of the activating mark H3K36me3 across the genome, with MYC's genomic locus being the most differentially affected v. H3.3 wild-type [48]. A synthetic lethality screen of 714 kinases in pediatric gliomas identified checkpoint kinase 1 (CHK1) and aurora kinase A (AURKA), both MYC stabilizing proteins, and usage of a small molecule inhibitor of AURKA (VX-689) exhibited potent cell killing in vitro (Table 2). Early neural development genes were also shown to be G34R/V activated, and a later study revealed MYC alone could induce stem-like phenotypes dependent on H3K4 methylation levels regulated by lysine-specific demethylase 1 (LSD1) [49]. Whether the G34R/V mechanism of tumorigenesis is dependent on, concurrent with, or completely independent of the LSD1-MYC interaction remains to be investigated (Figure 1). 
Table 2. Experimental pre-clinical therapeutics for pediatric high-grade gliomas including compound name, target of therapy, rationale for use in this disease, and references.

\begin{tabular}{|c|c|c|c|}
\hline \multicolumn{4}{|c|}{ Pre-Clinical Therapies for Pediatric High-Grade Gliomas } \\
\hline Compound(s) & Target & Rationale & Reference \\
\hline $\begin{array}{l}\text { VX-689 (renamed } \\
\text { MK-5108) }\end{array}$ & $\begin{array}{l}\text { AURKA } \\
\text { (Aurora kinase A) }\end{array}$ & Destabilizes MYC & [48] \\
\hline MI-2 & $\begin{array}{l}\text { MEN1 } \\
\text { (Menin) }\end{array}$ & $\begin{array}{l}\text { Blocks menin-MLL-AF9 initiated } \\
\text { leukemic oncogenesis; exact role in } \\
\text { glioma undefined }\end{array}$ & {$[50,51]$} \\
\hline GSK-J4 & $\begin{array}{l}\text { JMJD3 } \\
\text { (Jumonji-domain demethylase) }\end{array}$ & $\begin{array}{l}\text { Prevents further demethylation of } \\
\text { H3K27 mark in H3-K27M mutated } \\
\text { glioma }\end{array}$ & [52] \\
\hline $\begin{array}{l}\text { OTX-015 } \\
\text { JQ1 }\end{array}$ & $\begin{array}{l}\text { BRD2/3/4 } \\
\text { (Bromodomain-containing proteins) }\end{array}$ & $\begin{array}{l}\text { Interrupts BRD } \rightarrow \text { H3-acetylation } \\
\text { binding that is increased by } \\
\text { H3.3-K27M }\end{array}$ & [53-55] \\
\hline $\begin{array}{l}\text { GSK126 } \\
\text { GSK343 } \\
\text { EPZ-6438 }\end{array}$ & $\begin{array}{l}\text { EZH2 } \\
\text { (Enhancer of zeste homolog 2) }\end{array}$ & $\begin{array}{l}\text { De-represses tumor suppressor } \\
\text { p16 } 6^{\mathrm{INK} 4 \mathrm{a}} \text { and induces apoptosis }\end{array}$ & [55-57] \\
\hline BMS-754807 & $\begin{array}{l}\text { Multi-kinase, most potent against IGF-1R } \\
\text { (Insulin-like growth factor } 1 \text { receptor) }\end{array}$ & $\begin{array}{l}\text { Effective in compound screen; } \\
\text { multiple valid targets in DIPG }\end{array}$ & [58] \\
\hline PTC-209 & $\begin{array}{l}\text { BMI-1 } \\
\text { (polycomb group RING finger protein 4) }\end{array}$ & $\begin{array}{l}\text { Induces cell cycle arrest and } \\
\text { telomerase downregulation, reduces } \\
\text { migration, increases sensitivity to } \\
\text { radiotherapy }\end{array}$ & {$[59,60]$} \\
\hline
\end{tabular}

Given the role of G34R/V in modulating early neural oncogenesis, it remained to be seen if the K27M mutation would result in a similar fate. Using human embryonic stem cells (hESCs) as a model system, it was observed that transduced H3.3-K27M in combination with p53 silencing and constituently active platelet-derived growth factor receptor A (PDGFRA) conferred neoplastic traits to the cells. A small-molecule screen of $>80$ epigenetic compounds revealed menin (MEN1) as a potent target specific to K27M-possessing cells [50]. Menin is found in the trithorax histone methyltransferase complex and functions as either a tumor suppressor or an oncogene depending on the cell type. Further study is needed to determine the mechanistic role it plays in H3.3-K27M pediatric glioma as well as a safety/efficacy profile for the MEN1 inhibitor MI-2 [51] (Figure 1, Table 2). Screens on the genetic level using CRISPR-Cas9 have also been used in adult glioma models [61], setting the stage for H3.1/3.3-specific investigation and potential gene therapy applications.

Potential also exists to target epigenetic proteins that participate in the pathways interrupted by H3-K27M-mediated PRC2 inactivation. The hypomethylation signature at H3K27 can potentially be reversed by inhibiting histone $\mathrm{H} 3$ demethylases, in particular the ubiquitously transcribed tetratricopeptide repeat, $X$ chromosome (UTX) and Jumonji-domain 3 (JMJD3) demethylases, which are specific to the H3K27 mark. A small-molecule inhibitor of UTX/JMJD3, dubbed GSKJ4, was found to have efficacy in cell lines expressing H3.3-K27M, but displayed no effect in H3.3-G34R/V or wild-type H3.3 controls [52] (Table 2). The exact mechanistic action of the growth inhibition and apoptosis induced by GSKJ4 remains to be explored, as changes in H3K27me2/3 status can broadly affect gene expression (Figure 1). While PRC2 inactivation has been a prime molecular focus of DIPG mutations, the PRC1 complex has recently come to light as a therapeutic target. Single-cell RNA-Seq studies defined the PRC1 subunit BMI-1 to be upregulated in K27M DIPG cancer stem cells with an oligodendrocyte precursor (OPC) phenotype [60]. The authors and others [59] could target BMI-1 with the small molecule PTC-209 and found strong combinatorial effects with PDGFRA CRISPR-Cas9 knockouts (Table 2). As such, the more clinically advanced BMI-1 inhibitor PTC-596 is currently in clinical trials for DIPG and pHGG (NCT03605550).

Chromatin-association studies using Drosophila melanogaster confirmed the results of Lewis et al. [20], finding H3.3-K27M-containing nucleosomes to be enriched in H3K27 acetylation. A key additional observation was increased presence on these same nucleosomes of bromodomain 
and extra-terminal motif (BET) proteins BRD1 and BRD4 which function to "read" histone acetylation marks [62]. This suggests use of inhibitors of the BRD family as a therapeutic option in K27M-mutated DIPG, and indeed the pan-BET inhibitor JQ1 has displayed anti-tumor efficacy in pre-clinical models [53,54] (Table 2). Concurrent research examined the use of EZH2 inhibitors, either as a single agent [56] or in combination with BET inhibitors [55]. The mechanism of EZH2 inhibitor tumor suppression was found to be re-expression of p16 and subsequent apoptosis [56], but this could not be recapitulated in a genetically-engineered mouse model of H3.3-K27M DIPG [57] (Table 2). Of note is that the oncogenic driver mutation BRAF-V600E, present in a small subset of pHGG, may also benefit from epigenetic therapy. Recent studies have shown EZH2 to be an oncogene in BRAF-driven melanoma [63], and combination therapy of the BRAF inhibitor vemurafinib with JQ1 [64] or DNA methyltransferase inhibitor decitabine [65] displayed efficacy in pre-clinical melanoma models. In clinical studies, a Phase IIa clinical trial of the pan-BET inhibitor OTX-015 in recurrent adult glioblastoma (NCT02296476) was terminated prior to completion, and a pediatric screening trial that includes an EZH2 inhibitor is currently recruiting (NCT03155620). As such, the potential of BET and EZH2 inhibition in pHGG populations remains inconclusive (Figure 1).

High-throughput approaches to find viable "hits" further validated the use of demethylase inhibitors, with GSKJ4 displaying a strong synergistic effect when combined with the pan-histone deacetylase inhibitor (HDACi) panobinostat [66]. As expected, use of these drugs together increased $\mathrm{H} 3$ acetylation along with H3K27 methylation. Biochemical analyses of K27M-PRC2 interactions demonstrated that acetylation of $\mathrm{H} 3$ at various lysine residues could reverse PRC2 inactivation by over 80-fold [67], but whether this is the main mechanism of panobinostat in K27M models remains to be determined. HDAC inhibitors have previously been shown to be effective against adult glioma [68] and glial stem cells [69], with their efficacy enhanced by inhibiting LSD1. It is currently unknown if dual inhibition of LSD1 (H3K4 demethylation) and UTX/JMJD3 (H3K27 demethylation) can influence HDAC inhibitor-induced cell death, either in adult glioma or H3-mutated pediatric DIPG.

While Grasso et al. [66] used human xenografts of DIPG, later use of panobinostat in an immune-competent genetically-engineered mouse model of DIPG replicated the in vitro potency of panobinostat but found dose-limiting toxicities when administered in vivo. Panobinostat is well known to cause peripheral thrombocytopenia [70,71], which is not unexpected as it was initially FDA-approved for the blood cancer multiple myeloma. Recent clinical trial data presented at ISPNO 2018 confirms the dose-limiting toxicities of panobinostat when administered peripherally in pediatric patients [72]. Other HDAC inhibitors have been tested in pHGG; however, a retrospective study of valproic acid found no significant enhancement of treatments including radiation and DNA damaging and demethylating agents [73]. Lack of statistical power and dosage of valproic acid as an anticonvulsant, instead of for its HDAC properties, leaves the use of valproic acid in pHGG inconclusive on the clinical end (Figure 1). Given that the only positive in vivo data using HDAC inhibitors in pHGG utilized convection-enhanced delivery directly to the pons [66], alternative delivery strategies of small molecules and biologics to the dense tumor tissue may hold the key to successful pHGG therapy.

\section{Therapeutic Delivery}

A crucial challenge in glioma drug development is sufficient delivery to the brain, involving passage through the blood-brain barrier (BBB) when a compound is given systemically. Recent work has shown brainstem gliomas have less than one-third the tumor volume and possess lower rates of BBB permeability versus cortical gliomas, independent of H3.3 mutation status [74]. Panobinostat and GSKJ4 were verified in murine brain tissue via paired high-performance liquid chromatography (HPLC)/mass spectrometry (MS) $[52,66]$ but as of yet only panobinostat is in pediatric trials (Table 1). The pharmacokinetics of VX-689, MI-2, OTX-015, EZH2 inhibitors, and PTC-596 in the brain remain unknown, while studies on a multi-kinase drug (BMS-754807) demonstrated efficacy against 
H3.3-K27M murine cells in vitro but failed to reach $\mathrm{IC}_{50}$ levels in tumor tissue when dosed at $50 \mathrm{mg} / \mathrm{kg}$ in vivo [58] (Table 2).

Given these limitations, researchers need to think outside the current small-molecule therapeutic box. One method being explored is focused ultrasound (FUS), which aims to temporarily disrupt the tight junctions in the BBB to allow passage of drugs to the tumor site. It has shown limited efficacy in enhancement of temozolomide treatment [75], and a clinical trial is being pursued using doxorubicin (NCT02343991). This method can also be combined with "microbubbles" to further open the BBB [76], but FUS has not been tested with the epigenetic agents listed above. An even more exciting advancement uses a chain of iron-oxide nanospheres attached to a doxorubicin-loaded liposome. The nanospheres are coated with cyclic arginylglycylaspartic acid (RGD) and targeted to the $\alpha_{v} \beta_{3}$ integrin peptide that is overexpressed in brain tumor vasculature. This flexible "tail" of three iron-oxide spheres increases binding to the endothelial cells, and drug is subsequently released by a localized radio frequency (RF) field that the vibrates the tail and breaks open the liposome [77]. Further studies could adapt this technology to carry other drugs relevant to H3-mutated pediatric tumors, as well as increase drug penetrance to difficult-to-reach areas of the brain such as the pons in DIPG patients.

\section{Future Directions}

While we have explored promising small molecule approaches to treat pHGG, we must consider what role the immuno-oncology revolution will play in pediatric glioma patients going forward. The brain was previously thought to be an immune-privileged site, but this has been proven to not be the case [78]. All cells generate antigens on their cell surface corresponding to internal proteins, and recently researchers were able to isolate K27M-specific T-cells from DIPG patients [79], proving that the immune system can "see" the tumor and generate a reaction specific to its mutational status. Another K27M-driven immunotherapy target in DIPG is the lipid surface marker GD2, for which use of chimeric-antigen receptor T-cells (CAR-T) shows promise in pre-clinical models, but also displays cautionary inflammatory toxicities [80,81]. Furthermore, the potential use of expanded panels of epigenetic agents has been understudied in how it would affect immune function, both systemically and in the tumor microenvironment [82]. There also exists a tight interplay between cellular metabolism and epigenetic functions [83]; there may be other possibilities for modulation of these pathways through nutrient control and metabolic pathway inhibitors.

A large gap in knowledge of the biology of pHGG is in whether the epigenetic and kinase alterations observed in fully-formed tumors contribute to early oncogenesis of the tumor, or if they are only necessary for mature tumor maintenance. Kinase signaling through FGFR1 [84,85] and PDGFR [86] are crucial to normal CNS development as well as being potentially involved in recovery from radiation-induced necrosis [87], while the role of ACVR1 [88] in CNS function remains more mysterious. For H3.1/3.3 mutations, the highly conserved genotype for age and brain location points to proper $\mathrm{H} 3$ modification being involved in gene expression regulation during CNS maturation. It is possible that H3K27 methylation/acetylation is more important infratentorially while H3K36 methylation/acetylation is associated with supratentorial regulation. Complex in vivo models could answer these questions by modifying histones or their associated remodelers over periods of cortical maturation.

It is now understood adult and pediatric gliomas are distinct at the molecular level, a fact that was previously invisible pathologically and can be attributed to the genomics era of low-cost, high-quality sequencing. Rigorous and innovative research has shed new light on how epigenetic and kinase mutations contribute to pHGG molecular signaling. Standard of care currently remains unchanged, but rapidly developing targeted therapies and drug delivery methods are moving into clinical trials and may shift the treatment paradigm of pHGG in the coming years. There are several exciting avenues to pursue in pediatric glioma research, and fresh ideas and new approaches are desperately needed to combat this devastating illness. 
Author Contributions: Conceptualization, C.P.B. and J.C.; Writing-Original Draft Preparation, C.P.B.; Writing-Review \& Editing, S.M., W.Z., and J.C.; Visualization, M.F.; Supervision, J.C.

Funding: This research was funded by NIH/NINDS R21 NS093387, NIH/NCI Brain Cancer SPORE P50 CA127001, the Team Connor Foundation, the Marnie Rose Foundation, and the Thomas Scott Family Foundation, and supported by the NIH/NCI under award number P30CA016672. C.P.B. was funded by a Center for Cancer Epigenetics (CCE) Scholar award from MD Anderson Cancer Center.

Acknowledgments: We thank Richard R. Behringer, Rachel K. Miller, and Eric C. Swindell for helpful comments on the manuscript as well as classmates of C.P.B. for their unwavering support.

Conflicts of Interest: The authors declare no conflict of interest.

\section{References}

1. Ostrom, Q.T.; de Blank, P.M.; Kruchko, C.; Petersen, C.M.; Liao, P.; Finlay, J.L.; Stearns, D.S.; Wolff, J.E.; Wolinsky, Y.; Letterio, J.J.; et al. Alex's Lemonade Stand Foundation Infant and Childhood Primary Brain and Central Nervous System Tumors Diagnosed in the United States in 2007-2011. Neuro Oncol. 2015, 16 (Suppl. 10), x1-x36. [CrossRef]

2. Hoffman, L.M.; Veldhuijzen van Zanten, S.E.M.; Colditz, N.; Baugh, J.; Chaney, B.; Hoffmann, M.; Lane, A.; Fuller, C.; Miles, L.; Hawkins, C.; et al. Clinical, Radiologic, Pathologic, and Molecular Characteristics of Long-Term Survivors of Diffuse Intrinsic Pontine Glioma (DIPG): A Collaborative Report From the International and European Society for Pediatric Oncology DIPG Registries. J. Clin. Oncol. 2018, 36, 1963-1972. [CrossRef] [PubMed]

3. Louis, D.N.; Perry, A.; Reifenberger, G.; von Deimling, A.; Figarella-Branger, D.; Cavenee, W.K.; Ohgaki, H.; Wiestler, O.D.; Kleihues, P.; Ellison, D.W. The 2016 World Health Organization Classification of Tumors of the Central Nervous System: A summary. Acta Neuropathol. 2016, 131, 803-820. [CrossRef] [PubMed]

4. Merchant, T.E.; Pollack, I.F.; Loeffler, J.S. Brain tumors across the age spectrum: Biology, therapy, and late effects. Semin. Radiat. Oncol. 2010, 20, 58-66. [CrossRef] [PubMed]

5. Khatua, S.; Zaky, W. Diffuse intrinsic pontine glioma: Time for therapeutic optimism. CNS Oncol. 2014, 3, 337-348. [CrossRef] [PubMed]

6. Fangusaro, J. Pediatric high grade glioma: A review and update on tumor clinical characteristics and biology. Front. Oncol. 2012, 2, 105. [CrossRef] [PubMed]

7. Chamdine, O.; Gajjar, A. Molecular characteristics of pediatric high-grade gliomas. CNS Oncol. 2014, 3, 433-443. [CrossRef] [PubMed]

8. Bax, D.A.; Mackay, A.; Little, S.E.; Carvalho, D.; Viana-Pereira, M.; Tamber, N.; Grigoriadis, A.E.; Ashworth, A.; Reis, R.M.; Ellison, D.W.; et al. A distinct spectrum of copy number aberrations in pediatric high-grade gliomas. Clin. Cancer Res. 2010, 16, 3368-3377. [CrossRef] [PubMed]

9. Wu, G.; Broniscer, A.; McEachron, T.A.; Lu, C.; Paugh, B.S.; Becksfort, J.; Qu, C.; Ding, L.; Huether, R.; Parker, M.; et al. Somatic histone H3 alterations in pediatric diffuse intrinsic pontine gliomas and non-brainstem glioblastomas. Nat. Genet. 2012, 44, 251-253. [CrossRef] [PubMed]

10. Schwartzentruber, J.; Korshunov, A.; Liu, X.Y.; Jones, D.T.; Pfaff, E.; Jacob, K.; Sturm, D.; Fontebasso, A.M.; Quang, D.A.; Tonjes, M.; et al. Driver mutations in histone H3.3 and chromatin remodelling genes in paediatric glioblastoma. Nature 2012, 482, 226-231. [CrossRef] [PubMed]

11. Khuong-Quang, D.A.; Buczkowicz, P.; Rakopoulos, P.; Liu, X.Y.; Fontebasso, A.M.; Bouffet, E.; Bartels, U.; Albrecht, S.; Schwartzentruber, J.; Letourneau, L.; et al. K27M mutation in histone H3.3 defines clinically and biologically distinct subgroups of pediatric diffuse intrinsic pontine gliomas. Acta Neuropathol. 2012, 124, 439-447. [CrossRef] [PubMed]

12. Taylor, K.R.; Mackay, A.; Truffaux, N.; Butterfield, Y.; Morozova, O.; Philippe, C.; Castel, D.; Grasso, C.S.; Vinci, M.; Carvalho, D.; et al. Recurrent activating ACVR1 mutations in diffuse intrinsic pontine glioma. Nat. Genet. 2014, 46, 457-461. [CrossRef] [PubMed]

13. Wu, G.; Diaz, A.K.; Paugh, B.S.; Rankin, S.L.; Ju, B.; Li, Y.; Zhu, X.; Qu, C.; Chen, X.; Zhang, J.; et al. The genomic landscape of diffuse intrinsic pontine glioma and pediatric non-brainstem high-grade glioma. Nat. Genet. 2014, 46, 444-450. [CrossRef] [PubMed] 
14. Fontebasso, A.M.; Papillon-Cavanagh, S.; Schwartzentruber, J.; Nikbakht, H.; Gerges, N.; Fiset, P.O.; Bechet, D.; Faury, D.; De Jay, N.; Ramkissoon, L.A.; et al. Recurrent somatic mutations in ACVR1 in pediatric midline high-grade astrocytoma. Nat. Genet. 2014, 46, 462-466. [CrossRef] [PubMed]

15. Buczkowicz, P.; Hoeman, C.; Rakopoulos, P.; Pajovic, S.; Letourneau, L.; Dzamba, M.; Morrison, A.; Lewis, P.; Bouffet, E.; Bartels, U.; et al. Genomic analysis of diffuse intrinsic pontine gliomas identifies three molecular subgroups and recurrent activating ACVR1 mutations. Nat. Genet. 2014, 46, 451-456. [CrossRef] [PubMed]

16. Schroeder, K.M.; Hoeman, C.M.; Becher, O.J. Children are not just little adults: Recent advances in understanding of diffuse intrinsic pontine glioma biology. Pediatr. Res. 2014, 75, 205-209. [CrossRef] [PubMed]

17. Mackay, A.; Burford, A.; Carvalho, D.; Izquierdo, E.; Fazal-Salom, J.; Taylor, K.R.; Bjerke, L.; Clarke, M.; Vinci, M.; Nandhabalan, M.; et al. Integrated Molecular Meta-Analysis of 1,000 Pediatric High-Grade and Diffuse Intrinsic Pontine Glioma. Cancer Cell 2017, 32. [CrossRef] [PubMed]

18. Vanan, M.I.; Eisenstat, D.D. Management of high-grade gliomas in the pediatric patient: Past, present, and future. Neurooncol. Pract. 2014, 1, 145-157. [CrossRef] [PubMed]

19. Johnson, A.; Severson, E.; Gay, L.; Vergilio, J.A.; Elvin, J.; Suh, J.; Daniel, S.; Covert, M.; Frampton, G.M.; Hsu, S.; et al. Comprehensive Genomic Profiling of 282 Pediatric Low- and High-Grade Gliomas Reveals Genomic Drivers, Tumor Mutational Burden, and Hypermutation Signatures. Oncologist 2017, 22, 1478-1490. [CrossRef] [PubMed]

20. Lewis, P.W.; Muller, M.M.; Koletsky, M.S.; Cordero, F.; Lin, S.; Banaszynski, L.A.; Garcia, B.A.; Muir, T.W.; Becher, O.J.; Allis, C.D. Inhibition of PRC2 activity by a gain-of-function $\mathrm{H} 3$ mutation found in pediatric glioblastoma. Science 2013, 340, 857-861. [CrossRef] [PubMed]

21. Chan, K.M.; Fang, D.; Gan, H.; Hashizume, R.; Yu, C.; Schroeder, M.; Gupta, N.; Mueller, S.; James, C.D.; Jenkins, R.; et al. The histone H3.3K27M mutation in pediatric glioma reprograms H3K27 methylation and gene expression. Genes Dev. 2013, 27, 985-990. [CrossRef] [PubMed]

22. Bender, S.; Tang, Y.; Lindroth, A.M.; Hovestadt, V.; Jones, D.T.; Kool, M.; Zapatka, M.; Northcott, P.A.; Sturm, D.; Wang, W.; et al. Reduced H3K27me3 and DNA hypomethylation are major drivers of gene expression in K27M mutant pediatric high-grade gliomas. Cancer Cell 2013, 24, 660-672. [CrossRef] [PubMed]

23. Wen, H.; Li, Y.; Xi, Y.; Jiang, S.; Stratton, S.; Peng, D.; Tanaka, K.; Ren, Y.; Xia, Z.; Wu, J.; et al. ZMYND11 links histone H3.3K36me3 to transcription elongation and tumour suppression. Nature 2014, 508, $263-268$. [CrossRef] [PubMed]

24. Jakacki, R.I.; Cohen, K.J.; Buxton, A.; Krailo, M.D.; Burger, P.C.; Rosenblum, M.K.; Brat, D.J.; Hamilton, R.L.; Eckel, S.P.; Zhou, T.; et al. Phase 2 study of concurrent radiotherapy and temozolomide followed by temozolomide and lomustine in the treatment of children with high-grade glioma: A report of the Children's Oncology Group ACNS0423 study. Neuro Oncol. 2016, 18, 1442-1450. [CrossRef] [PubMed]

25. Friedman, H.S.; Prados, M.D.; Wen, P.Y.; Mikkelsen, T.; Schiff, D.; Abrey, L.E.; Yung, W.K.; Paleologos, N.; Nicholas, M.K.; Jensen, R.; et al. Bevacizumab alone and in combination with irinotecan in recurrent glioblastoma. J. Clin. Oncol. 2009, 27, 4733-4740. [CrossRef] [PubMed]

26. Chinot, O.L.; Wick, W.; Mason, W.; Henriksson, R.; Saran, F.; Nishikawa, R.; Carpentier, A.F.; Hoang-Xuan, K.; Kavan, P.; Cernea, D.; et al. Bevacizumab plus radiotherapy-temozolomide for newly diagnosed glioblastoma. N. Engl. J. Med. 2014, 370, 709-722. [CrossRef] [PubMed]

27. Gilbert, M.R.; Dignam, J.J.; Armstrong, T.S.; Wefel, J.S.; Blumenthal, D.T.; Vogelbaum, M.A.; Colman, H.; Chakravarti, A.; Pugh, S.; Won, M.; et al. A randomized trial of bevacizumab for newly diagnosed glioblastoma. N. Engl. J. Med. 2014, 370, 699-708. [CrossRef] [PubMed]

28. Wick, W.; Gorlia, T.; Bendszus, M.; Taphoorn, M.; Sahm, F.; Harting, I.; Brandes, A.A.; Taal, W.; Domont, J.; Idbaih, A.; et al. Lomustine and Bevacizumab in Progressive Glioblastoma. N. Engl. J. Med. 2017, 377, 1954-1963. [CrossRef] [PubMed]

29. Grill, J.; Massimino, M.; Bouffet, E.; Azizi, A.A.; McCowage, G.; Cañete, A.; Saran, F.; Le Deley, M.C.; Varlet, P.; Morgan, P.S.; et al. Phase II, Open-Label, Randomized, Multicenter Trial (HERBY) of Bevacizumab in Pediatric Patients With Newly Diagnosed High-Grade Glioma. J. Clin. Oncol. 2018, 36, 951-958. [CrossRef] [PubMed] 
30. Mackay, A.; Burford, A.; Molinari, V.; Jones, D.T.W.; Izquierdo, E.; Brouwer-Visser, J.; Giangaspero, F.; Haberler, C.; Pietsch, T.; Jacques, T.S.; et al. Molecular, Pathological, Radiological, and Immune Profiling of Non-brainstem Pediatric High-Grade Glioma from the HERBY Phase II Randomized Trial. Cancer Cell 2018, 33, 829-842.e5. [CrossRef] [PubMed]

31. Xu, C.; Liu, X.; Geng, Y.; Bai, Q.; Pan, C.; Sun, Y.; Chen, X.; Yu, H.; Wu, Y.; Zhang, P.; et al. Patient-derived DIPG cells preserve stem-like characteristics and generate orthotopic tumors. Oncotarget 2017, 8, 76644-76655. [CrossRef] [PubMed]

32. Zhang, L.; Pan, C.-C.; Li, D. The historical change of brainstem glioma diagnosis and treatment: From imaging to molecular pathology and then molecular imaging. Chin. Neurosurg. J. 2015, 1, 4. [CrossRef]

33. Hamisch, C.; Kickingereder, P.; Fischer, M.; Simon, T.; Ruge, M.I. Update on the diagnostic value and safety of stereotactic biopsy for pediatric brainstem tumors: A systematic review and meta-analysis of 735 cases. J. Neurosurg. Pediatr. 2017, 20, 261-268. [CrossRef] [PubMed]

34. Carai, A.; Mastronuzzi, A.; De Benedictis, A.; Messina, R.; Cacchione, A.; Miele, E.; Randi, F.; Esposito, G.; Trezza, A.; Colafati, G.S.; et al. Robot-Assisted Stereotactic Biopsy of Diffuse Intrinsic Pontine Glioma: A Single-Center Experience. World Neurosurg. 2017, 101, 584-588. [CrossRef] [PubMed]

35. Huang, T.Y.; Piunti, A.; Lulla, R.R.; Qi, J.; Horbinski, C.M.; Tomita, T.; James, C.D.; Shilatifard, A.; Saratsis, A.M. Detection of Histone H3 mutations in cerebrospinal fluid-derived tumor DNA from children with diffuse midline glioma. Acta Neuropathol. Commun. 2017, 5, 28. [CrossRef] [PubMed]

36. Clymer, J.; Kieran, M.W. The Integration of Biology Into the Treatment of Diffuse Intrinsic Pontine Glioma: A Review of the North American Clinical Trial Perspective. Front. Oncol. 2018, 8, 169. [CrossRef] [PubMed]

37. Gaspar, N.; Marshall, L.; Perryman, L.; Bax, D.A.; Little, S.E.; Viana-Pereira, M.; Sharp, S.Y.; Vassal, G.; Pearson, A.D.; Reis, R.M.; et al. MGMT-independent temozolomide resistance in pediatric glioblastoma cells associated with a PI3-kinase-mediated HOX/stem cell gene signature. Cancer Res. 2010, 70, 9243-9252. [CrossRef] [PubMed]

38. Kurscheid, S.; Bady, P.; Sciuscio, D.; Samarzija, I.; Shay, T.; Vassallo, I.; Criekinge, W.V.; Daniel, R.T.; van den Bent, M.J.; Marosi, C.; et al. Chromosome 7 gain and DNA hypermethylation at the HOXA10 locus are associated with expression of a stem cell related HOX-signature in glioblastoma. Genome Biol. 2015, 16, 16. [CrossRef] [PubMed]

39. Costa, B.M.; Smith, J.S.; Chen, Y.; Chen, J.; Phillips, H.S.; Aldape, K.D.; Zardo, G.; Nigro, J.; James, C.D.; Fridlyand, J.; et al. Reversing HOXA9 oncogene activation by PI3K inhibition: Epigenetic mechanism and prognostic significance in human glioblastoma. Cancer Res. 2010, 70, 453-462. [CrossRef] [PubMed]

40. Arrowsmith, C.H.; Audia, J.E.; Austin, C.; Baell, J.; Bennett, J.; Blagg, J.; Bountra, C.; Brennan, P.E.; Brown, P.J.; Bunnage, M.E.; et al. The promise and peril of chemical probes. Nat. Chem. Biol. 2015, 11, 536-541. [CrossRef] [PubMed]

41. Gharbi, S.I.; Zvelebil, M.J.; Shuttleworth, S.J.; Hancox, T.; Saghir, N.; Timms, J.F.; Waterfield, M.D. Exploring the specificity of the PI3K family inhibitor LY294002. Biochem. J. 2007, 404, 15-21. [CrossRef] [PubMed]

42. Dittmann, A.; Werner, T.; Chung, C.W.; Savitski, M.M.; Falth Savitski, M.; Grandi, P.; Hopf, C.; Lindon, M.; Neubauer, G.; Prinjha, R.K.; et al. The commonly used PI3-kinase probe LY294002 is an inhibitor of BET bromodomains. ACS Chem. Biol. 2014, 9, 495-502. [CrossRef] [PubMed]

43. Wu, Y.L.; Maachani, U.B.; Schweitzer, M.; Singh, R.; Wang, M.; Chang, R.; Souweidane, M.M. Dual Inhibition of PI3K/AKT and MEK/ERK Pathways Induces Synergistic Antitumor Effects in Diffuse Intrinsic Pontine Glioma Cells. Transl. Oncol. 2017, 10, 221-228. [CrossRef] [PubMed]

44. Miyahara, H.; Yadavilli, S.; Natsumeda, M.; Rubens, J.A.; Rodgers, L.; Kambhampati, M.; Taylor, I.C.; Kaur, H.; Asnaghi, L.; Eberhart, C.G.; et al. The dual mTOR kinase inhibitor TAK228 inhibits tumorigenicity and enhances radiosensitization in diffuse intrinsic pontine glioma. Cancer Lett. 2017, 400, 110-116. [CrossRef] [PubMed]

45. Venkatesh, H.S.; Tam, L.T.; Woo, P.J.; Lennon, J.; Nagaraja, S.; Gillespie, S.M.; Ni, J.; Duveau, D.Y.; Morris, P.J.; Zhao, J.J.; et al. Targeting neuronal activity-regulated neuroligin-3 dependency in high-grade glioma. Nature 2017, 549, 533-537. [CrossRef] [PubMed]

46. Becher, O.J.; Gilheeney, S.W.; Khakoo, Y.; Lyden, D.C.; Haque, S.; De Braganca, K.C.; Kolesar, J.M.; Huse, J.T.; Modak, S.; Wexler, L.H.; et al. A phase I study of perifosine with temsirolimus for recurrent pediatric solid tumors. Pediatr. Blood Cancer 2017, 64. [CrossRef] [PubMed] 
47. Nikbakht, H.; Panditharatna, E.; Mikael, L.G.; Li, R.; Gayden, T.; Osmond, M.; Ho, C.Y.; Kambhampati, M.; Hwang, E.I.; Faury, D.; et al. Spatial and temporal homogeneity of driver mutations in diffuse intrinsic pontine glioma. Nat. Commun. 2016, 7, 11185. [CrossRef] [PubMed]

48. Bjerke, L.; Mackay, A.; Nandhabalan, M.; Burford, A.; Jury, A.; Popov, S.; Bax, D.A.; Carvalho, D.; Taylor, K.R.; Vinci, M.; et al. Histone H3.3. mutations drive pediatric glioblastoma through upregulation of MYCN. Cancer Discov. 2013, 3, 512-519. [CrossRef] [PubMed]

49. Kozono, D.; Li, J.; Nitta, M.; Sampetrean, O.; Gonda, D.; Kushwaha, D.S.; Merzon, D.; Ramakrishnan, V.; Zhu, S.; Zhu, K.; et al. Dynamic epigenetic regulation of glioblastoma tumorigenicity through LSD1 modulation of MYC expression. Proc. Natl. Acad. Sci. USA 2015, 112, E4055-E4064. [CrossRef] [PubMed]

50. Funato, K.; Major, T.; Lewis, P.W.; Allis, C.D.; Tabar, V. Use of human embryonic stem cells to model pediatric gliomas with H3.3K27M histone mutation. Science 2014, 346, 1529-1533. [CrossRef] [PubMed]

51. Grembecka, J.; He, S.; Shi, A.; Purohit, T.; Muntean, A.G.; Sorenson, R.J.; Showalter, H.D.; Murai, M.J.; Belcher, A.M.; Hartley, T.; et al. Menin-MLL inhibitors reverse oncogenic activity of MLL fusion proteins in leukemia. Nat. Chem. Biol. 2012, 8, 277-284. [CrossRef] [PubMed]

52. Hashizume, R.; Andor, N.; Ihara, Y.; Lerner, R.; Gan, H.; Chen, X.; Fang, D.; Huang, X.; Tom, M.W.; Ngo, V.; et al. Pharmacologic inhibition of histone demethylation as a therapy for pediatric brainstem glioma. Nat. Med. 2014, 20, 1394-1396. [CrossRef] [PubMed]

53. Piunti, A.; Hashizume, R.; Morgan, M.A.; Bartom, E.T.; Horbinski, C.M.; Marshall, S.A.; Rendleman, E.J.; Ma, Q.; Takahashi, Y.H.; Woodfin, A.R.; et al. Therapeutic targeting of polycomb and BET bromodomain proteins in diffuse intrinsic pontine gliomas. Nat. Med. 2017, 23, 493-500. [CrossRef] [PubMed]

54. Nagaraja, S.; Vitanza, N.A.; Woo, P.J.; Taylor, K.R.; Liu, F.; Zhang, L.; Li, M.; Meng, W.; Ponnuswami, A.; Sun, W.; et al. Transcriptional Dependencies in Diffuse Intrinsic Pontine Glioma. Cancer Cell 2017, 31, 635-652. [CrossRef] [PubMed]

55. Zhang, Y.; Dong, W.; Zhu, J.; Wang, L.; Wu, X.; Shan, H. Combination of EZH2 inhibitor and BET inhibitor for treatment of diffuse intrinsic pontine glioma. Cell Biosci. 2017, 7, 56. [CrossRef] [PubMed]

56. Mohammad, F.; Weissmann, S.; Leblanc, B.; Pandey, D.P.; Hojfeldt, J.W.; Comet, I.; Zheng, C.; Johansen, J.V.; Rapin, N.; Porse, B.T.; et al. EZH2 is a potential therapeutic target for H3K27M-mutant pediatric gliomas. Nat. Med. 2017, 23, 483-492. [CrossRef] [PubMed]

57. Cordero, F.J.; Huang, Z.; Grenier, C.; He, X.; Hu, G.; McLendon, R.E.; Murphy, S.K.; Hashizume, R.; Becher, O.J. Histone H3.3K27M Represses p16 to Accelerate Gliomagenesis in a Murine Model of DIPG. Mol. Cancer Res. 2017, 15, 1243-1254. [CrossRef] [PubMed]

58. Halvorson, K.G.; Barton, K.L.; Schroeder, K.; Misuraca, K.L.; Hoeman, C.; Chung, A.; Crabtree, D.M.; Cordero, F.J.; Singh, R.; Spasojevic, I.; et al. A high-throughput in vitro drug screen in a genetically engineered mouse model of diffuse intrinsic pontine glioma identifies BMS-754807 as a promising therapeutic agent. PLoS ONE 2015, 10, e0118926. [CrossRef] [PubMed]

59. Kumar, S.S.; Sengupta, S.; Lee, K.; Hura, N.; Fuller, C.; DeWire, M.; Stevenson, C.B.; Fouladi, M.; Drissi, R. BMI-1 is a potential therapeutic target in diffuse intrinsic pontine glioma. Oncotarget 2017, 8, 62962-62975. [CrossRef] [PubMed]

60. Filbin, M.G.; Tirosh, I.; Hovestadt, V.; Shaw, M.L.; Escalante, L.E.; Mathewson, N.D.; Neftel, C.; Frank, N.; Pelton, K.; Hebert, C.M.; et al. Developmental and oncogenic programs in H3K27M gliomas dissected by single-cell RNA-seq. Science 2018, 360, 331-335. [CrossRef] [PubMed]

61. Zuckermann, M.; Hovestadt, V.; Knobbe-Thomsen, C.B.; Zapatka, M.; Northcott, P.A.; Schramm, K.; Belic, J.; Jones, D.T.; Tschida, B.; Moriarity, B.; et al. Somatic CRISPR/Cas9-mediated tumour suppressor disruption enables versatile brain tumour modelling. Nat. Commun. 2015, 6, 7391. [CrossRef] [PubMed]

62. Herz, H.M.; Morgan, M.; Gao, X.; Jackson, J.; Rickels, R.; Swanson, S.K.; Florens, L.; Washburn, M.P.; Eissenberg, J.C.; Shilatifard, A. Histone H3 lysine-to-methionine mutants as a paradigm to study chromatin signaling. Science 2014, 345, 1065-1070. [CrossRef] [PubMed]

63. Zingg, D.; Debbache, J.; Peña-Hernández, R.; Antunes, A.T.; Schaefer, S.M.; Cheng, P.F.; Zimmerli, D.; Haeusel, J.; Calçada, R.R.; Tuncer, E.; et al. EZH2-Mediated Primary Cilium Deconstruction Drives Metastatic Melanoma Formation. Cancer Cell 2018, 34. [CrossRef] [PubMed]

64. Nakamura, Y.; Hattori, N.; Iida, N.; Yamashita, S.; Mori, A.; Kimura, K.; Yoshino, T.; Ushijima, T. Targeting of super-enhancers and mutant BRAF can suppress growth of BRAF-mutant colon cancer cells via repression of MAPK signaling pathway. Cancer Lett. 2017, 402, 100-109. [CrossRef] [PubMed] 
65. Zakharia, Y.; Monga, V.; Swami, U.; Bossler, A.D.; Freesmeier, M.; Frees, M.; Khan, M.; Frydenlund, N.; Srikantha, R.; Vanneste, M.; et al. Targeting epigenetics for treatment of BRAF mutated metastatic melanoma with decitabine in combination with vemurafenib: A phase lb study. Oncotarget 2017, 8, 89182-89193. [CrossRef] [PubMed]

66. Grasso, C.S.; Tang, Y.; Truffaux, N.; Berlow, N.E.; Liu, L.; Debily, M.A.; Quist, M.J.; Davis, L.E.; Huang, E.C.; Woo, P.J.; et al. Functionally defined therapeutic targets in diffuse intrinsic pontine glioma. Nat. Med. 2015, 21,555-559. [CrossRef] [PubMed]

67. Brown, Z.Z.; Muller, M.M.; Jain, S.U.; Allis, C.D.; Lewis, P.W.; Muir, T.W. Strategy for “detoxification" of a cancer-derived histone mutant based on mapping its interaction with the methyltransferase PRC2. J. Am. Chem. Soc. 2014, 136, 13498-13501. [CrossRef] [PubMed]

68. Singh, M.M.; Manton, C.A.; Bhat, K.P.; Tsai, W.W.; Aldape, K.; Barton, M.C.; Chandra, J. Inhibition of LSD1 sensitizes glioblastoma cells to histone deacetylase inhibitors. Neuro Oncol. 2011, 13, 894-903. [CrossRef] [PubMed]

69. Singh, M.M.; Johnson, B.; Venkatarayan, A.; Flores, E.R.; Zhang, J.; Su, X.; Barton, M.; Lang, F.; Chandra, J. Preclinical activity of combined HDAC and KDM1A inhibition in glioblastoma. Neuro Oncol. 2015, 17, 1463-1473. [CrossRef] [PubMed]

70. Drappatz, J.; Lee, E.Q.; Hammond, S.; Grimm, S.A.; Norden, A.D.; Beroukhim, R.; Gerard, M.; Schiff, D.; Chi, A.S.; Batchelor, T.T.; et al. Phase I study of panobinostat in combination with bevacizumab for recurrent high-grade glioma. J. Neurooncol. 2012, 107, 133-138. [CrossRef] [PubMed]

71. Lee, E.Q.; Reardon, D.A.; Schiff, D.; Drappatz, J.; Muzikansky, A.; Grimm, S.A.; Norden, A.D.; Nayak, L.; Beroukhim, R.; Rinne, M.L.; et al. Phase II study of panobinostat in combination with bevacizumab for recurrent glioblastoma and anaplastic glioma. Neuro Oncol. 2015, 17, 862-867. [CrossRef] [PubMed]

72. Cooney, T.; Onar-Thomas, A.; Huang, J.; Lulla, R.; Fangusaro, J.; Kramer, K.; Baxter, P.; Fouladi, M.; Dunkel, I.J.; Warren, K.E.; et al. Dipg-22. A phase 1 trial of the histone deacetylase inhibitor panobinostat in pediatric patients with recurrent or refractory diffuse intrinsic pontine glioma: A pediatric brain tumor consortium (pbtc) study. Neuro Oncol. 2018, 20. [CrossRef]

73. Masoudi, A.; Elopre, M.; Amini, E.; Nagel, M.E.; Ater, J.L.; Gopalakrishnan, V.; Wolff, J.E. Influence of valproic acid on outcome of high-grade gliomas in children. Anticancer Res. 2008, 28, 2437-2442. [PubMed]

74. Subashi, E.; Cordero, F.J.; Halvorson, K.G.; Qi, Y.; Nouls, J.C.; Becher, O.J.; Johnson, G.A. Tumor location, but not H3.3K27M, significantly influences the blood-brain-barrier permeability in a genetic mouse model of pediatric high-grade glioma. J. Neurooncol. 2016, 126, 243-251. [CrossRef] [PubMed]

75. Wei, K.C.; Chu, P.C.; Wang, H.Y.; Huang, C.Y.; Chen, P.Y.; Tsai, H.C.; Lu, Y.J.; Lee, P.Y.; Tseng, I.C.; Feng, L.Y.; et al. Focused ultrasound-induced blood-brain barrier opening to enhance temozolomide delivery for glioblastoma treatment: A preclinical study. PLoS ONE 2013, 8, e58995. [CrossRef] [PubMed]

76. Fan, C.H.; Ting, C.Y.; Liu, H.L.; Huang, C.Y.; Hsieh, H.Y.; Yen, T.C.; Wei, K.C.; Yeh, C.K. Antiangiogenic-targeting drug-loaded microbubbles combined with focused ultrasound for glioma treatment. Biomaterials 2013, 34, 2142-2155. [CrossRef] [PubMed]

77. Peiris, P.M.; Abramowski, A.; McGinnity, J.; Doolittle, E.; Toy, R.; Gopalakrishnan, R.; Shah, S.; Bauer, L.; Ghaghada, K.B.; Hoimes, C.; et al. Treatment of Invasive Brain Tumors Using a Chain-like Nanoparticle. Cancer Res. 2015, 75, 1356-1365. [CrossRef] [PubMed]

78. Absinta, M.; Ha, S.K.; Nair, G.; Sati, P.; Luciano, N.J.; Palisoc, M.; Louveau, A.; Zaghloul, K.A.; Pittaluga, S.; Kipnis, J.; et al. Human and nonhuman primate meninges harbor lymphatic vessels that can be visualized noninvasively by MRI. Elife 2017, 6. [CrossRef] [PubMed]

79. Chheda, Z.S.; Kohanbash, G.; Okada, K.; Jahan, N.; Sidney, J.; Pecoraro, M.; Yang, X.; Carrera, D.A.; Downey, K.M.; Shrivastav, S.; et al. Novel and shared neoantigen derived from histone 3 variant H3.3K27M mutation for glioma T cell therapy. J. Exp. Med. 2018, 215, 141-157. [CrossRef] [PubMed]

80. Mount, C.W.; Majzner, R.G.; Sundaresh, S.; Arnold, E.P.; Kadapakkam, M.; Haile, S.; Labanieh, L.; Hulleman, E.; Woo, P.J.; Rietberg, S.P.; et al. Potent antitumor efficacy of anti-GD2 CAR T cells in H3-K27M(+) diffuse midline gliomas. Nat. Med. 2018, 24, 572-579. [CrossRef] [PubMed]

81. Richman, S.A.; Nunez-Cruz, S.; Moghimi, B.; Li, L.Z.; Gershenson, Z.T.; Mourelatos, Z.; Barrett, D.M.; Grupp, S.A.; Milone, M.C. High-Affinity GD2-Specific CAR T Cells Induce Fatal Encephalitis in a Preclinical Neuroblastoma Model. Cancer Immunol. Res. 2018, 6, 36-46. [CrossRef] [PubMed] 
82. Bailey, C.; Romero, M.; Han, R.; Larson, J.; Becher, O.; Lee, D.; Monje, M.; Gopalakrishnan, V.; Zaky, W.; Chandra, J. Immu-19. LSD1 modulates nk cell immunotherapy through an onco-immunogenic gene signature in dipg. Neuro Oncol. 2018, 20. [CrossRef]

83. Reid, M.A.; Dai, Z.; Locasale, J.W. The impact of cellular metabolism on chromatin dynamics and epigenetics. Nat. Cell Biol. 2017, 19, 1298-1306. [CrossRef] [PubMed]

84. Baron, O.; Förthmann, B.; Lee, Y.W.; Terranova, C.; Ratzka, A.; Stachowiak, E.K.; Grothe, C.; Claus, P.; Stachowiak, M.K. Cooperation of nuclear fibroblast growth factor receptor 1 and Nurr1 offers new interactive mechanism in postmitotic development of mesencephalic dopaminergic neurons. J. Biol. Chem. 2012, 287, 19827-19840. [CrossRef] [PubMed]

85. Choubey, L.; Collette, J.C.; Smith, K.M. Quantitative assessment of fibroblast growth factor receptor 1 expression in neurons and glia. Peerj 2017, 5, e3173. [CrossRef] [PubMed]

86. Funa, K.; Sasahara, M. The roles of PDGF in development and during neurogenesis in the normal and diseased nervous system. J. Neuroimmune Pharmacol. 2014, 9, 168-181. [CrossRef] [PubMed]

87. Miyata, T.; Toho, T.; Nonoguchi, N.; Furuse, M.; Kuwabara, H.; Yoritsune, E.; Kawabata, S.; Kuroiwa, T.; Miyatake, S. The roles of platelet-derived growth factors and their receptors in brain radiation necrosis. Radiat. Oncol. 2014, 9, 51. [CrossRef] [PubMed]

88. Pacifici, M.; Shore, E.M. Common mutations in ALK2/ACVR1, a multi-faceted receptor, have roles in distinct pediatric musculoskeletal and neural orphan disorders. Cytokine Growth Factor Rev. 2016, 27, 93-104. [CrossRef] [PubMed]

(C) 2018 by the authors. Licensee MDPI, Basel, Switzerland. This article is an open access article distributed under the terms and conditions of the Creative Commons Attribution (CC BY) license (http://creativecommons.org/licenses/by/4.0/). 